\title{
Genotypes of pathogenic Leptospira spp isolated from rodents in Argentina
}

\author{
Sylvia Grune Loffler ${ }^{1 /}$, Maria Elisa Pavan², Bibiana Vanasco ${ }^{3}$, Luis Samartino ${ }^{1,4}$, Olga Suarez ${ }^{5}$, \\ Carmelo Auteri', Graciela Romero', Bibiana Brihuega, ${ }^{1,4}$
}

\begin{abstract}
${ }^{1}$ Laboratorio de Leptospirosis, Instituto de Patobiología, Centro de Investigación en Ciencias Veterinarias y Agronómicas, Instituto Nacional de Tecnología Agropecuaria Castelar, Buenos Aires, Argentina ${ }^{2}$ Laboratorio de Biología Molecular, Biochemiq SA, Buenos Aires, Argentina ${ }^{3}$ Instituto Nacional de Enfermedades Respiratorias Dr E Coni, Administración Nacional de Laboratorios e Institutos de Salud Dr Carlos G Malbrán, Santa Fe, Argentina ${ }^{4}$ Bacteriología y Micología, Facultad de Veterinaria, Universidad del Salvador, Pilar, Buenos Aires, Argentina ${ }^{5}$ Departamento de Ecología, Genética y Evolución, Facultad de Ciencias Naturales y Exactas, Universidad de Buenos Aires, Buenos Aires, Argentina
\end{abstract}

Leptospirosis is the most widespread zoonosis in the world and significant efforts have been made to determine and classify pathogenic Leptospira strains. This zoonosis is maintained in nature through chronic renal infections of carrier animals, with rodents and other small mammals serving as the most important reservoirs. Additionally, domestic animals, such as livestock and dogs, are significant sources of human infection. In this study, a multiple-locus variable-number tandem repeat analysis (MLVA) was applied to genotype 22 pathogenic Leptospira strains isolated from urban and periurban rodent populations from different regions of Argentina. Three MLVA profiles were identified in strains belonging to the species Leptospira interrogans (serovars Icterohaemorrhagiae and Canicola); one profile was observed in serovar Icterohaemorrhagiae and two MLVA profiles were observed in isolates of serovars Canicola and Portlandvere. All strains belonging to Leptospira borgpetersenii serovar Castellonis exhibited the same MLVA profile. Four different genotypes were isolated from urban populations of rodents, including both mice and rats and two different genotypes were isolated from periurban populations.

Key words: Leptospira spp - pathogenic - multiple-locus variable-number tandem repeat analysis genotyping - rodent population - Argentina

Leptospirosis is the most widespread zoonotic disease in the world. It is caused by pathogenic Leptospira spp spirochetes, which find an ideal niche for transmission in subtropical and tropical regions. There are no available data on the incidence of leptospirosis in several countries and the disease is frequently not recognised and is therefore severely neglected (Hartskeerl et al. 2011). Pathogenic Leptospira strains mainly infect mammals, but they can also be found in reptiles and amphibians (Levett 2001, Adler \& Moctezuma 2010). This zoonosis is maintained in nature through chronic renal infection of carrier animals, with rodents and other small mammals being the most important reservoirs. Additionally, livestock and domestic animals, such as dogs, are significant sources of human infection. In Argentina, this disease is endemic and no epidemiological control or prevention programs targeting leptospirosis have been implemented thus far. From 2012 until July of 2013, an estimated 1,056 human cases were reported to the National Health Ministry, 99 of which were confirmed as

doi: 10.1590/0074-0276140295

Financial support: Proyecto Nacional INTA, AESA 202821

SGL has a postgraduate CONICET scholarship.

+ Corresponding author: sgrune@cnia.inta.gov.ar

Received 3 June 2013

Accepted 27 November 2013 leptospirosis (MS 2013). Recently, Draghi et al. (2011) reported the presence of leptospirosis in cattle from Corrientes province, which is endemic for this disease. An outbreak in this province in 2009 resulted in the death of 100 calves in one week, demonstrating the significance of leptospirosis in this region.

The occurrence of leptospirosis has also been reported in the rodent populations of urban and periurban areas of Argentina (Cacchione et al. 1967, Cacchione 1973, Arango et al. 2001, Martin et al. 2002, Marder et al. 2008, Scialfa et al. 2010), but no information on the molecular characteristics of the Leptospira strains infecting these animals is available.

Several schemes for the genotyping of the pathogenic species of Leptospira spp have been developed around the world in recent years (Cerqueira \& Picardeau 2009, Cerqueira et al. 2009, Levett \& Haake 2010, Nalam et al. 2010). Multiple-locus variable-number tandem repeat analysis (MLVA) has been successfully employed to genotype pathogenic Leptospira spp strains (Majed et al. 2005, Slack et al. 2005, 2006, Salaün et al. 2006, Pavan et al. 2008, 2011a, Li et al. 2012). Using this methodology, Pavan et al. (2011b) identified eight distinct MLVA genotypes in the Leptospira spp isolated from domestic animals and humans from Argentina.

The present study applied MLVA to molecularly characterise a collection of strains isolated from urban and periurban rodents, including Rattus norvegicus, Rattus rattus, Rattus sp. and Mus musculus, from the Argentine provinces of Buenos Aires, Santa Fe and Entre Ríos. 


\section{MATERIALS AND METHODS}

Strains - Twenty-two pathogenic Leptospira spp strains were genotyped. Six of these strains were isolated during the years 2009-2011 and 16 of the strains were part of the bacterial collection of the Leptospirosis Laboratory at the Pathobiology Institute of the Argentine National Institute of Agricultural Technology, which is a World Organization for Animal Health reference laboratory. The isolates used in this study were previously serotyped using the cross agglutinin absorption test (Pavan et al. 2008). The sources, dates and the locations of isolation for the strain are listed in Tables I, II. The reference Leptospira interrogans strains employed in this study were Pomona (serovar Pomona, serogroup Pomona), M20 (serovar Copenhageni, serogroup Icterohaemorrhagiae), RGA and Ictero No. 1 (serovar Icterohaemorrhagiae, serogroup Icterohaemorrhagiae), Hond Utrecht IV (serovar Canicola, serogroup Canicola) and MY 1039 (serovar Portlandvere, serogroup Canicola). The reference strain used for Leptospira borgpetersenii was Castellon3 (serovar Castellonis, serogroup Ballum).

Genotyping - The reference strains and isolates were grown in Fletcher medium (Difco Laboratories) at $28^{\circ} \mathrm{C}$. The MLVA strain typing procedure was performed as described by Majed et al. (2005), Salaün et al. (2006) and Pavan et al. (2008). Briefly, $100 \mu \mathrm{L}$ of a culture sample was incubated at $100^{\circ} \mathrm{C}$ for $10 \mathrm{~min}$ and this suspension was used as the DNA template. MLVA typing was performed using two sets of oligonucleotides specific for pathogenic L. interrogans, Leptospira kirschneri and L. borgpetersenii. Oligonucleotides that hybridised to the flanking regions of the VNTR4, VNTR7, VNTR9, VNTR10, VNTR19, VNTR23 and VNTR31 loci were used to discriminate strains of $L$. interrogans and oligonucleotides that hybridised to the flanking regions of the VNTR4, VNTR7, VNTR10, Lb4 and Lb5 loci were used for L. kirschneri, L. borgpetersenii and L. interrogans strains (Majed et al. 2005, Salaün et al. 2006). The final volume $(50 \mu \mathrm{L})$ of each reaction mixture contained polymerase chain reaction (PCR) buffer (20 mM Tris-HCl, pH 8.4, 50 mM KCL), $200 \mu \mathrm{M}$ deoxynucleoside triphosphates, $2 \mu \mathrm{M}$ each of the corresponding forward and reverse primers, $2 \mathrm{mM}$ $\mathrm{MgCl}_{2}, 1.25 \mathrm{U}$ of Taq DNA polymerase (Invitrogen) and $5 \mu \mathrm{L}$ of DNA template. PCR amplifications were carried out in a Thermo Scientific PxE 0.2 Thermal Cycler, using the following cycling parameters: $94^{\circ} \mathrm{C}$ for $5 \mathrm{~min}$, followed by 35 cycles of denaturalisation at $94^{\circ} \mathrm{C}$ for $30 \mathrm{~s}$, annealing at $55^{\circ} \mathrm{C}$ for $30 \mathrm{~s}$ and extension at $72^{\circ} \mathrm{C}$ for $90 \mathrm{~s}$, with a final cycle at $72^{\circ} \mathrm{C}$ for 10 min. The amplified samples were examined following electrophoresis in ethidium bromide-containing $2 \%$ agarose gels in TAE buffer (40 mM Tris-acetate, $1 \mathrm{mM}$ EDTA, pH 8.0) at $100 \mathrm{~V}$ for $50 \mathrm{~min}$. Amplified DNA bands were visualised through ultraviolet light expo-

TABLE I

Strains of Leptospira interrogans typed in this paper with the seven loci described by Majed et al. (2005)

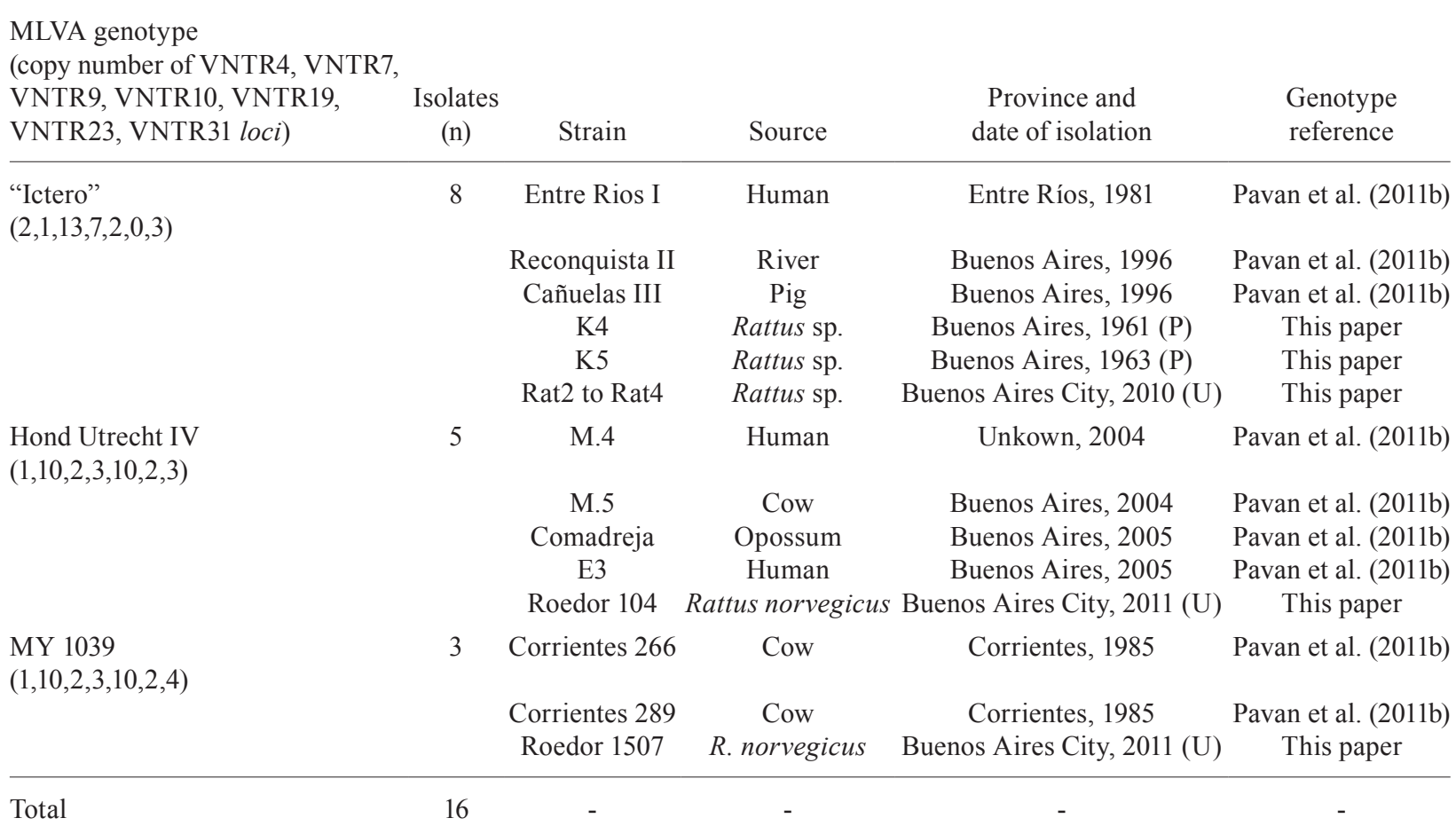

strains isolated from periurban and urban rodent populations are marked with (P) and (U), respectively. MLVA: multiple-locus variable-number tandem repeat analysis. 
sure (Uvi Tec transiluminator BTS-20.M, Manufacturer UviTec, St. John's Innovation Centre, Cowley Road, Cambride, England). Amplicon sizes were estimated using CienMarker (Biodynamics) and the GelAnalyzer 2010a program. To calculate repeat copy numbers, the following formula was used: number of repeats $(b p)=$ [fragment size (bp) - flanking regions (bp)]/ repeat size (bp). Repeat copy numbers were rounded down to the closest whole number. If the copy number was less than one, it was rounded to zero.

\section{RESULTS}

The MLVA profiles of 22 pathogenic strains isolated from periurban and urban rodent populations were analysed in this study based on seven loci described by Majed et al. (2005) and five loci described by Salaün et al. (2006) (Tables I, II). All of the strains analysed in this study were also characterised using agglutination absorption tests, which generated the same results as the MLVA typing. A total of seven strains belonged to $L$. interrogans. Five strains presented an MLVA profile $(2,1,13,7,2,0,3)$ that was indistinguishable from that of strains M20 (serovar Copenhageni) and Ictero No. 1 (serovar Icterohaemorrhagiae) (Majed et al. 2005), both of which come from serogroup Icterohaemorrhagiae. Two of these strains were isolated from periurban rodent specimens from Buenos Aires province (K4 and K5) and three were isolated from urban rodents [Rattus sp. in the city of Buenos Aires (Rat2, Rat3 and Rat4)]. Additionally, two strains were isolated from urban rodents (R. norvegicus). One of these strains was characterised as serovar Portlandvere strain (Roedor 1507) which showed the same MLVA profile $(1,10,2,3,10,2,4)$ as MY 1039. The other was characterised as serovar Canicola (Roedor 104) and showed the same profile as Hond Utrecht IV $(1,10,2,3,10,2,3)$. Additionally, we identified 15 strains belonging to $L$. borgpetersenii, all of which presented the MLVA pattern $(1,-, 1,4,6)$ of Castellon 3 (serovar Castellonis). Six of these strains were isolated from periurban rodents, including one strain (C16) from
M. musculus in Buenos Aires province and five (ROE1ROE5) from $R$. rattus in Entre Rios province. The other nine isolates came from urban rodent populations, with a total of eight strains being isolated from M. musculus in the city of Santa Fe (Santa Fe I to Santa Fe VIII) and one strain (Rat 1) being isolated from Rattus sp. in city of Buenos Aires. The sources, locations and dates of collection for the isolated strains examined in this study are indicated in Tables I, II.

In this study, we used both sets of MLVA typing primers described by Majed et al. (2005) and Salaün et al. (2006) to genotype all three pathogenic Leptospira species found in Argentina. No L. kirschneri genotypes were found in the rodent isolates obtained in this work. The newly isolated strains were included in serogroup Icterohaemorrhagiae and serogroup Canicola. Five new strains isolated from Rattus sp. (K4, K5, Rat2, Rat3 Rat4) were added to serogroup Icterohaemorrhagiae, represented by the reference strains M20, RGA and Ictero I. This MLVA pattern had previously been found in strains isolated from pigs (Cañuelas III) and humans (Entre Rios I) and in an isolate from a water sample from a river (Reconquista II); all of these samples were isolated in the provinces of Buenos Aires and Entre Rios (Pavan et al. 2011b). In addition to the serogroup Canicola strains present in Argentina, Portlandvere (MY 1039) has been found in strains isolated from cows (Corrientes 289 and Corrientes 266, from Corrientes province) and rodents (Roedor 1507, isolated from $R$. norvegicus in the city of Buenos Aires). The Leptospira spp strains from Buenos Aires province that corresponded to the MLVA profile of Hond Utrecht IV were represented by strains isolated from a white-eared opossum (Didelphis albiventris, opossum), a rodent ( $R$. norvegicus, Roedor 104), cows (M5) and humans (E3 and M4). Serovar Castellonis (Castellon 3) was more homogeneous and included only isolates from rodents found in the urban and periurban areas of the Santa Fe, Entre Rios and Buenos Aires provinces, confirming that the strains harbouring this genotype were circulating pathogenic strains.

TABLE II

Strains of Leptospira borgpetersenii typed in this study using the five loci described by Salaün et al. (2006)

\begin{tabular}{|c|c|c|c|c|c|}
\hline $\begin{array}{l}\text { MLVA genotype } \\
\text { (copy number of VNTR4, VNTR7 } \\
\text { VNTR10, Lb4 and Lb5 loci) }\end{array}$ & $\begin{array}{c}\text { Isolates } \\
\text { (n) }\end{array}$ & Strain & Source & $\begin{array}{l}\text { Province and } \\
\text { date of isolation }\end{array}$ & $\begin{array}{l}\text { Genotype } \\
\text { reference }\end{array}$ \\
\hline \multirow[t]{4}{*}{$\begin{array}{l}\text { Castellon3 } \\
(1,0,1,4,6)\end{array}$} & 1 & $\mathrm{C} 16$ & Mus musculus & $\begin{array}{c}\text { Buenos Aires, } \\
\text { year unknown }(\mathrm{P})\end{array}$ & This paper \\
\hline & 8 & Santa Fe I to Santa Fe VIII & M. musculus & Santa Fe City, 1998 (U) & This paper \\
\hline & 5 & ROE1 to ROE5 & Rattus rattus & Paraná, 2006 (P) & This paper \\
\hline & 1 & Rat1 & Rattus sp. & Buenos Aires City, 2010 (U) & This paper \\
\hline Total & 15 & - & - & - & - \\
\hline
\end{tabular}

strains isolated from periurban and urban rodent populations are marked with (P) and (U), respectively. MLVA: multiple-locus variable-number tandem repeat analysis. 


\section{DISCUSSION}

Different rodent species have been described as reservoirs of distinct Leptospira spp serovars (Levett 2001, Vanasco et al. 2003, Levett \& Haake 2010, Vedhagiri et al. 2010, Hartskeerl et al. 2011). Rats have been found to carry the Icterohaemorrhagiae or Copenhageni serovars, while leptospires isolated from mice have been shown to belong to serogroup Ballum. Hartskeerl et al. (2011) proposed that the main reservoirs of pathogenic and highly virulent serovars are rodents and this is the reason why leptospires (and leptospirosis) are unlikely to be eradicated.

In contrast to previous reports (Zuerner \& Alt 2009), this study showed that tandem repeat analysis (using VNTRs and MLVA) was unable to achieve a higher resolution (stratification) than the serotyping of isolates from Argentina. We genotyped a strain isolated from Rattus sp. in the city of Buenos Aires that presented an MLVA profile identical to that of Canicola Portlandvere MY 1039. The MY 1039 MLVA profile had previously only been reported in cows from Corrientes province (Pavan et al. 2011b). New wildlife carriers can be determined through strain isolation and molecular typing methods. Using this approach, Brihuega et al. (2007) isolated and genotyped a L. interrogans Canicola Canicola Hond Utrecht IV strain from $D$. albiventris (white-eared opossum) in a rural area in Buenos Aires province. This genotype has also been isolated from strains from rats (this work), cows and humans (Pavan et al. 2011b). On the other hand, the whiteeared opossum ( $D$. albiventris) seems to be a candidate for the environmental dissemination of $L$. borgpetersenii (Jorge et al. 2012). In this study, 142 R. norvegicus and a number of opossums from 10 domiciles of patients with leptospirosis were captured and examined. The infecting serovar in the rat population was Copenhageni and rats could be identified as an important leptospiral reservoir. L. borgpetersenii Castellonis was the pathogenic leptospire isolated from $D$. albiventris. In a recent study in New Caledonia (Pacific Ocean), Perez et al. (2011) obtained similar results for strains isolated from rats and mice. Using a multilocus sequence typing protocol, $L$. borgpetersenii Ballum was identified in isolates from and $L$. interrogans Icterohaemorrhagiae was identified in isolates from $R$. rattus and $R$. norvegicus (Perez et al. 2011). Moreover, an isolate recovered from $R$. norvegicus field rats in South India was identified as L. borgpetersenii serogroup Javanica (Vedhagiri et al. 2010). Previous studies performed in humans during a leptospirosis outbreak in 1998 in Santa Fe, Argentina, which occurred after excessive rain and floods, determined that human sera were reactive to the serotypes Ballum, Canicola, Icterohaemorrhagiae and Pyrogenes (Vanasco et al. 2000, 2003). Additionally, L. borgpetersenii strains isolated from rodents were serotyped as serovar Arborea serogroup Ballum (Vanasco et al. 2000).

In summary, 15 pathogenic $L$. interrogans and $L$. borgpetersenii strains were isolated from urban rodent populations (from Santa $\mathrm{Fe}$ and the city of Buenos Aires), which displayed a total of four different MLVA genotypes. Additionally, seven pathogenic strains were isolated from periurban rodent populations from Buenos
Aires and Entre Rios provinces and these strains contained both pathogenic species as well as two different genotypes. These results show that several MLVA genotypes have circulated among Argentine rodents in the last 50 years and the same genotype is sometimes shared by strains isolated from urban and periurban rodent populations.

\section{ACKNOWLEDGEMENTS}

To Dr Monica Jacobsen, for the revision of this paper.

\section{REFERENCES}

Adler B, Moctezuma AP 2010. Leptospira and leptospirosis. Vet Microbiol 27: 287-296.

Arango J, Cittadino E, Agostini A, De Mazzonelli GD, Alvarez C, Colusi M, Koval A, Britos AC, Kravetz F 2001. Prevalencia de leptospiras en Rattus rattus y Rattus norvegicus en el gran Buenos Aires, Argentina. Ecol Austral 11: 25-30.

Brihuega B, Pavan M, Cairó F, Venzano A, Auteri C, Funes D, Romero G, Samartino L 2007. Leptospira patógena en riñon de Didelphis albiventris (comadreja). Rev Argent Microbiol 39: 19.

Cacchione RA 1973. Enfoques de los estudios de las leptospirosis humana y animal en América Latina. Rev Argent Microbiol 1: 36-53.

Cacchione RA, Bulgini MJD, Cascelli ES, Martinez ES 1967. Leptospirosis en animales silvestres. Estado actual de sus investigaciones, aislamientos y clasificación de cepas argentinas. Rev Fac C Vet 20: 37-54.

Cerqueira GM, McBride AJ, Picardeau M, Ribeiro SG, Moreira AN, Morel V, Reis MG, Ko AI, Dellagostin OA 2009. Distribution of the leptospiral immunoglobin-like (lig) genes in pathogenic Leptospira species and application of ligB to typing leptospiral isolates. J Med Microbiol 58: 1173-1181.

Cerqueira GM, Picardeau M 2009. A century of Leptospira strain typing. Infect Genet Evol 9: 760-768.

Draghi MG, Brihuega B, Benítez D, Sala JM, Biotti GM, Pereyra M, Homse A, Guariniello L 2011. Brote de leptospirosis en terneros en recría en la provincia de Corrientes, Argentina. Rev Argent Microbiol 43: 42-44.

Hartskeerl RA, Collares-Pereira M, Ellis WA 2011. Emergence, control and re-emerging leptospirosis: dynamics of infection in the changing world. Clin Microbiol Infect 17: 494-501.

Jorge S, Hartleben C, Seixas F, Coimbra M, Stark C, Larrondo A, Amaral M, Albano AP, Minello LF, Dellagostin OA, Brod CS 2012. Leptospira borgpetersenii from free-living white-eared opossum (Didelphis albiventris): first isolation in Brazil. Acta Trop 124: 147-151.

Levett PN 2001. Leptospirosis. Clin microbiol Rev 14: 296-326.

Levett PN, Haake DA 2010. Leptospira species (leptospirosis). In GL Mandell, JE Bennett, R Dolin (eds.), Principles and practice of infectious diseases, Churchill Livingtsone Elsevier, Philadelphia, p. 3059-3065.

Li SJ, Zhang CC, Li XW, Tian KC, Tang GP, Wang DM, Liu Y, Nie YX, Jiang XG 2012. Molecular typing of Leptospira interrogans strains isolated from Rattus tanezumi in Guizhou province, South West of China. Biomed Enviorn Sci 25: 542-548.

Majed Z, Bellenger E, Postic D, Pourcel C, Baranton G, Picardeau M 2005. Identification of variable-number tandem-repeat loci in Leptospira interrogans sensu stricto. J Clin Microbiol 43: 539-545.

Marder G, Ruiz RM, Bottinelli OR, Peiretti HA, Zorzo L, Merino DE, Czernik GE 2008. Prevalencia de leptospirosis en roedores 
sinantrópicos de la Cuidad de Corrientes, Argentina. Rev Vet 19: $150-153$

Martin U, Sensevy A, Colombo J, Tramontin V 2002. Leptospirosis en la Provincia de Santa Fe - Descripción epidemiológica, clínica y socioeconómica. Medicina 62: 164-168.

MS - Ministerio de Salud Argentina 2013. Boletín integrado de vigilancia 177 SE 26, Secretaria de Promoción e Programas Sanitários, Buenos Aires, 123 pp.

Nalam K, Ahmed A, Devi SM, Francalacci P, Baig M, Sechi LA, Hartskeerl RA, Ahmed N 2010. Genetic affinities within a large global collection of pathogenic leptospira: implications for strain identification and molecular epidemiology. PLOS ONE 5: e12637.

Pavan ME, Brihuega B, Pettinari MJ, Cairó F 2011a. Multiple-locus variable-number tandem repeat analysis of reference strains used for the diagnosis of leptospirosis in Argentina. Rev Argent Microbiol 43: 251-255

Pavan ME, Cairó F, Brihuega B, Samartino L 2008. Multiple-locus variable-number tandem repeat analysis (MLVA) of Leptospira interrogans serovar Pomona from Argentina reveals four new genotypes. Comp Immunol Microbiol Infect Dis 31: 37-45.

Pavan ME, Cairó F, Pettinari MJ, Samartino L, Brihuega B 2011b. Genotyping of Leptospira interrogans strains from Argentina by multiple-locus variable-number tándem repeat analysis (MLVA). Comp Immunol Microbiol Infect Dis 34: 135-141.

Perez J, Brescia F, Becam J, Mauron C, Goarant C 2011. Rodent abundance dynamics and leptospirosis carriage in an area of hyper. Endemicity in New Caledonia. PLoS Negl Trop Dis 5: e1361.

Salaün L, Mérien F, Gurianova S, Baranton G, Picardeau M 2006. Application of multilocus variable-number tandem-repeat analysis for molecular typing of the agent of leptospirosis. J Clin Microbiol 44: 3954-3962.
Scialfa E, Bolpe J, Bardon JC, Ridao G, Gentile J, Gallicchio O 2010. Isolation of Leptospira interrogans from suburban rats in Tandil, Buenos Aires. Rev Argent Microbiol 42: 126-128.

Slack AT, Dohnt MF, Symonds ML, Smythe LD 2005. Development of a multiple-locus variable number of tandem repeat analysis (MLVA) for Leptospira interrogans and its application to Leptospira interrogans serovar Australis isolates from far North Queensland, Australia. Ann Clin Microbiol Antimicrob 4: 10.

Slack AT, Symonds M, Dohnt M, Smythe L 2006. An improved multiple-locus variable number of tandem repeats analysis for Leptospira interrogans serovar Australis: a comparison with fluorescent amplified fragment length polymorphism analysis and its use to redefine the molecular epidemiology of this serovar in Queensland, Australia. J Med Microbiol 55: 1549-1557.

Vanasco NB, Rossetti C, Sequeira G, Sequeira MD, Calderón G, Tarabla HD 2000. First isolations of leptospires serogroup Ballum serovar arbórea in Argentina. Vet Rec 147: 246-247.

Vanasco NB, Sequeira MD, Sequeira G, Tarabla HD 2003. Associations between leptospiral infection and seropositivity in rodents and environmental characteristics in Argentina. Prev Vet Med 60: 227-235.

Vedhagiri K, Natarajaseenivasan K, Prabhakaran SG, Selvin J, Narayanan R, Shouche Y, Vijayachari P, Ratnam S 2010. Characterization of Leptospira borgpetersenii isolates from field rats (Rattus norvegicus) by 16S RRNA and LipL32 gene sequences. Braz J Microbiol 41: 150-157.

Zuerner RL, Alt DT 2009. Variable nucleotide tandem-repeat analysis revealing a unique group of Leptospira interrogans serovars Pomona isolates associated with California sea lions. J Clin $\mathrm{Mi}$ crobiol 47: 1202-1205. 